\title{
Reputação Corporativa e a Criação de Riqueza nas EMPRESAS LISTADAS NA BM\&FBOVESPA
}

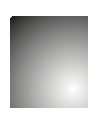

\author{
Corporate Reputation and Wealth Creation of \\ Companies Listed on BM\&FBovespa
}

Márcia Martins Mendes De Luca

Doutora em Controladoria e Contabilidade pela Universidade de São Paulo. Professora Associada da Universidade Federal do Ceará. Fortaleza, CE, Brasil.E-mail: marciadeluca@ufc.br

\section{Alan Diógenes Góis}

Mestre em Administração e Controladoria pela Universidade Federal do Ceará . Doutorando em Controladoria e Contabilidade na Universidade de São Paulo - USP. São Paulo, SP, Brasil. E-mail: alandgois@hotmail.com

Juliana Almeida Costa

Bacharel em Ciências Contábeis pela Universidade Federal do Ceará. Fortaleza, CE, Brasil. E-mail: juliana_costa92@hotmail.com

\section{Ana Jeniffer Rebouças Maia}

Graduanda em Ciências Contábeis pela Universidade Federal do Ceará. Fortaleza, CE, Brasil. E-mail: anajeniffer@gmail.com

\section{Resumo}

Este estudo tem como objetivo investigar a relação entre a reputação corporativa e a criação de riqueza pelas companhias listadas na BM\&FBovespa, considerando a Teoria da Sinalização. Fez-se uso da Regressão Linear Múltipla e do teste de MannWhitney em uma amostra de 309 empresas. A coleta de dados foi realizada com base nas Demonstrações Financeiras Padronizadas, no Formulário de Referência e na participação das empresas em alguns rankings. Os resultados revelaram que: (i) a criação de riqueza é influenciada pela reputação corporativa, assim como o tamanho, o endividamento, a proporção de ativos intangíveis, a idade e a internacionalização; (ii) há diferenças estatisticamente significantes entre as empresas com reputação e aquelas que não possuem reputação corporativa. Conclui-se que manter uma boa reputação corporativa, sendo esta considerada um ativo intangível, dificilmente copiada e proveniente dos sinais positivos emitidos para os stakeholders, constitui fator determinante na explicação da criação de riqueza.

Palavras-chave: Reputação Corporativa. Criação de Riqueza. Teoria da Sinalização.

\section{Abstract}

This study aims at investigating the relation between corporate reputation and the creation of wealth in companies listed on the BM\&FBovespa, considering the Signaling Theory. Multiple Linear Regression and Mann-Whitney's Test were employed on a sample of 309 companies. The gathering of data was performed based on Standardized Financial Statements, Reference Application Forms and the companies' participation in some rankings. The results revealed that (i) the creation of wealth is influenced by corporate reputation, as well as size, debts, proportion of intangible assets, age, and internationalization; (ii) there are statistically significant differences between companies with corporate reputation and companies without it. It is concluded that the maintenance of good corporate reputation, which is considered to be an intangible asset, and which is hard to copy as well as a result of positive signals emitted towards stakeholders, constitutes a determining factor when it comes to explaining the wealth created.

Keywords: Corporate Reputation. Creation of Wealth. Signaling Theory. 


\section{INTRODUÇÃO}

A reputação corporativa tem sido fator relevante na estratégia das empresas, pois propicia às empresas um diferencial competitivo essencial no cenário de globalização e concorrência acirrada. Sob essa perspectiva, alguns estudos destacam que a conquista $e$ a preservação de uma boa reputação corporativa propicia vantagens perante os concorrentes e consequente melhoria no desempenho econômico-financeiro (FOMBRUN; SHANLEY, 1990; ROBERTS; DOWLING, 2002; THOMAZ; BRITO, 2010; CAIXETA et al., 2011; SANTOS; PORTO, 2013). Isso pode ser alcançado a partir da postura das empresas no mercado; ou seja, uma vez praticando ações correspondentes à ética e à responsabilidade social, as empresas podem conquistar boa reputação. (GOMES et al., 2010)

Vale ressaltar que as atitudes socialmente responsáveis revelam as trajetórias estratégicas das empresas e suas perspectivas de futuro, o que pode ser percebido a partir de sua riqueza criada, e, consequentemente, propicia a melhoria de indicadores de desempenho, evidenciando o potencial corporativo para o alcance dos objetivos (FOMBRUN; SHANLEY, 1990; FOMBRUN; VAN RIEL, 1997; CAIXETA et al., 2011). Além disso, algumas pesquisas empíricas anteriores constataram que as empresas com boa reputação obtêm inúmeros outros benefícios. (FOMBRUN; SHANLEY, 1990; HERREMANS; AKATHAPORN; MCINNES, 1993; LANDON; SMITH, 1997; ROBERTS; DOWLING, 2002)

Segundo Roberts e Dowling (2002), a reputação corporativa consiste no conjunto de atributos organizacionais, desenvolvidos ao longo do tempo, que influencia a forma como os stakeholders percebem as empresas com boa conduta corporativa, também conhecida como boa cidadania corporativa. As ações empresariais socialmente responsáveis podem reforçar a relação das organizações com a comunidade e com os empregados, culminando na construção de uma boa reputação e, consequentemente, na criação de valor. (MACHADO FILHO, 2006)

Husted e Allen (2007) afirmam que as atividades da empresa podem agregar valor no momento em que reduzem custos, criam diferenciação do produto ou levam os clientes a transferir seu poder de compra de uma empresa para outra. Portanto, a criação de valor
- neste estudo, representada pela riqueza criada (valor adicionado) pelas empresas - por meio de práticas socialmente responsáveis advém da sinalização, por parte da empresa, de uma postura confiável, responsável e ética, e, principalmente, da forma como os gestores compreendem e incorporam tais práticas na estratégia empresarial.

Destarte, ao sinalizar para seus stakeholders que vêm operando com base também nos seus interesses, ou seja, que além de se preocupar em apresentar bom desempenho econômico, se preocupa também com as condições da sociedade e com a preservação do meio ambiente, por exemplo, a empresa conquista um julgamento positivo para a formação de uma boa reputação corporativa. Assim, com base no que aduz a Teoria da Sinalização, o comportamento das partes interessadas (stakeholders) sofre influência de acordo com os sinais positivos que as empresas apresentam ao mercado.

Diante do exposto, busca-se uma resposta para o seguinte questionamento: Qual a relação entre a reputação corporativa $e$ a riqueza criada pelas companhias de capital aberto? Para responder à questão de pesquisa proposta, o presente estudo tem como objetivo principal investigar a relação entre a reputação corporativa e a riqueza criada pelas companhias de capital aberto listadas na BM\&FBovespa. Adicionalmente, o estudo procura verificar se a riqueza criada pelas empresas com reputação corporativa é estatisticamente similar à riqueza criada pelas demais.

De cunho descritivo, com abordagem quantitativa, o estudo reúne uma amostra de 309 empresas de capital aberto listadas na BM\&FBovespa, na posição de 2 de setembro de 2013. A boa reputação corporativa considerou a participação das empresas nos seguintes rankings: as marcas mais valiosas do Brasil (ISTOÉ DINHEIRO, 2012), as 500 maiores empresas por vendas (EXAME, 2012), as 100 maiores empresas por valor de mercado (EXAME, 2012) e as empresas mais admiradas no Brasil (CARTA CAPITAL, 2012). Já a coleta de dados referentes à riqueza criada e demais variáveis econômico-financeiras foi realizada com base nas Demonstrações Financeiras Padronizadas e no Formulário de Referência, de cada uma das empresas da amostra, disponíveis no website da BM\&FBovespa.

Cabe destacar que a relevância desta pesquisa reside na emergência da discussão do tema reputação 
corporativa, haja vista sua ainda incipiente exploração e abordagem empírica, nos estudos acadêmicos, principalmente no âmbito nacional. Vale ressaltar a, sempre importante, busca por aspectos que possam explicar a conquista de melhor desempenho, nesse caso, representada pela criação de riqueza (valor adicionado) das companhias, que, segundo Riahi-Belkaoui (1992), proporciona uma melhor imagem das políticas de reinvestimento, na medida em que separa os fundos gerados internamente, além de servir de indicador de desempenho. Finalmente, é possível justificar esta pesquisa pela inovadora discussão dos temas em sinergia - reputação corporativa e criação de riqueza - , sob a fundamentação dos pressupostos da Teoria da Sinalização.

\section{Referencial Teórico}

Além da apresentação dos conceitos de reputação corporativa e criação de riqueza, assim como a relação entre ambos os conceitos sob os preceitos da Teoria da Sinalização, essa seção expõe os resultados de alguns estudos empíricos anteriores nacionais $e$ internacionais que verificaram a associação entre a reputação corporativa, o desempenho empresarial e a criação de riqueza.

\subsection{Reputação Corporativa e Criação de Riqueza à luz da Teoria da Sinalização}

Para aplicar seu capital em uma empresa, o investidor tende a observar uma série de características do empreendimento em que pretende arriscar parte de seu patrimônio. Nesse contexto, a apresentação de informações voluntárias por parte das empresas vem se fazendo cada dia mais necessária para evidenciar uma postura de mais transparência (KLANN; BEUREN, 2011). Assim, os stakeholders examinam todos os atos da firma, visto que eles afetam ou podem afetar de alguma maneira o seu valor de mercado. (GONZÁLEZ, 1998)

Ao reforçar a importância da transparência, Spence (1973) e Dalmácio et al. (2013) afirmam que a Teoria da Sinalização trata dos problemas de assimetria informacional nos mercados, e que por meio da sinalização de mais informações essa assimetria pode ser reduzida. Os autores asseveram que os sinais funcionam como mecanismos de discriminação, num ambiente de assimetria informacional, sendo capazes de alterar as crenças e a forma como os stakeholders percebem o contexto organizacional.

Fombrun e Shanley (1990) alegam que a partir dos "sinais" emitidos pelas empresas, os stakeholders, por meio de julgamentos coletivos, criam reputações que estratificam as organizações em seus ramos de atividade e conferem vantagem competitiva àquelas percebidas como mais bem reputadas.

Criada por meio de julgamentos coletivos de diversos stakeholders, a reputação é, atualmente, tratada sob as diferentes perspectivas, dependendo da formação e do interesse daqueles que trabalham com o tema (CASTRO, 2008), não havendo um consenso para a sua definição. Fombrun, Gardberg e Sever (2000) veem a reputação corporativa como um construto que agrega a percepção de vários stakeholders sobre o desempenho de uma empresa, mas que, ao mesmo tempo, é individualizado para cada grupo. Dessa forma, admitem que há diferentes reputações, na medida das diferenças de percepção entre os grupos de stakeholders.

Assim, uma das dificuldades em definir reputação diz respeito à sua relação com os construtos de imagem e identidade. Pode-se conjecturar que essa repetição de comportamentos da organização gera imagens que, na percepção dos stakeholders, traduzem sua conduta e formam sua reputação, favorável ou desfavorável, definindo o comportamento futuro esperado da organização (FOMBRUN; SHANLEY, 1990). Assim, a imagem corporativa corresponde à avaliação que cada indivíduo faz da empresa a partir de seu conjunto de sentimentos e crenças (DOWLING, 2001). Dito isso, percebe-se que a imagem é passível de construção, já que pode ser alterada, transformada, adaptada, conforme o desempenho organizacional. (CHUN, 2005)

A identidade corporativa, por sua vez, é definida como os símbolos e a nomenclatura, tais como logomarcas e slogans promocionais utilizados pela organização para se identificar perante seus stakeholders. (DOWLING, 2001)

De acordo com Thomaz e Brito (2010), a reputação se desenvolve ao longo do tempo, e resulta de interações repetidas e de experiências acumuladas nos relacionamentos com a organização. Já para Sánchez e Sotorrío (2007), a reputação é um conjunto de 
atributos econômicos e não econômicos, criados a partir de suas ações passadas, razão pela qual pode ser considerada também uma variável resultante da estratégia da empresa.

Hall (1992) identifica várias particularidades da reputação, a saber: o seu fraco peso no contexto legal, o seu efeito diferenciador, a sua capacidade de representar um conjunto de conhecimentos e emoções dos indivíduos, a sua atuação como um fator de defesa de uma estima e a incapacidade da reputação para ser comercializada.

Jorge (2010) defende que a reputação não pode ser transacional, e que o seu valor é de difícil mensuração. Ela representa o grau de estima e de confiança que os stakeholders têm na organização e, consequentemente, o grau da sua preferência para trabalhar, investir e fazer negócio. O autor persevera, ainda, que a reputação é única, de modo que personifica a identidade organizacional e protege a organização das tentativas da concorrência em copiar e imitar as suas práticas, traduzindo-se numa vantagem competitiva.

Portanto, quando há evidências de um desempenho favorável, a reputação corporativa emerge como um recurso potencial para a obtenção da vantagem competitiva, por não ser facilmente copiada (BALMER; GREYSER, 2003). Assim, se a boa reputação corporativa é um recurso valioso, intuitivamente se espera que, mantendo-se constantes as demais condições, o valor de uma empresa com boa reputação seja superior ao de empresas com menor reputação. (HORIUCHI, 2010)

Segundo Dowling (2006), os benefícios gerados por uma boa reputação corporativa, apesar de não serem claramente identificados nas demonstrações financeiras, por se tratar de ativo intangível, podem ser verificados no valor de mercado da própria empresa, além de se refletir em mais receitas ou menos despesas, incluindo as despesas evitadas, resultando em maior valor para a empresa. (HORIUCHI, 2010)

Peteraf e Barney (2003) afirmam que às empresas com desempenho superior atribui-se a existência de uma vantagem competitiva, isto é, uma capacidade de criação de valor acima da média dos concorrentes, proporcionada pela boa reputação. Dessa forma, pode-se afirmar que a reputação corporativa está também atrelada à criação de riqueza, levando em conta sua vantagem competitiva e potencial de apresentar melhor desempenho.

A riqueza criada pela empresa, bem como sua distribuição com os elementos que contribuem para a sua formação, é apresentada na Demonstração do Valor Adicionado (DVA) (SANTOS, 2007), que faz parte do conjunto de demonstrações financeiras divulgado pelas empresas junto ao mercado. $\mathrm{O}$ valor adicionado consignado na DVA refere-se ao aumento da riqueza gerada pelo uso dos recursos da empresa e é calculado, regra geral, pela diferença entre o valor das vendas e o dos insumos adquiridos de terceiros. (DE LUCA et al., 2009)

Verifica-se, portanto, à luz da Teoria da Sinalização, que a reputação corporativa se relaciona com a criação de valor, neste estudo representada pela riqueza criada (valor adicionado), conforme modelo teórico do estudo mostrado na Figura 1.

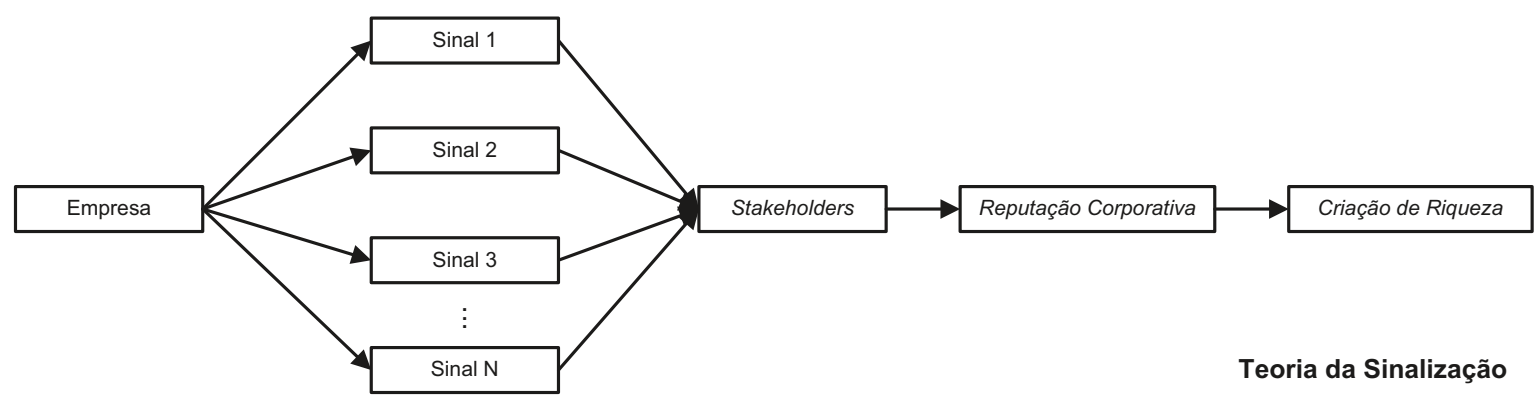

Figura 1: Modelo Teórico do Estudo

Fonte: Elaborada pelos autores deste artigo 
Observa-se que a reputação corporativa possui diversas definições, características e efeitos para as organizações. Para o presente estudo, adota-se a definição de Fombrun e Van Riel (1997), segundo os quais a reputação corporativa é um dos vários atributos intangíveis que embora difíceis de mensurar, criam valor para as empresas. Destarte, considerando os preceitos da Teoria da Sinalização e as recomendações da literatura sobre a inter-relação da reputação corporativa com a criação de valor, procura-se testar a seguinte hipótese de pesquisa: A reputação corporativa das companhias de capital aberto está positivamente relacionada com a sua criação de riqueza.

\subsection{Estudos Empíricos Anteriores}

Segundo Brito e Brito (2011), muitos estudos utilizam as variáveis de desempenho empresarial para mensurar a vantagem competitiva, sendo esta responsável pela criação de valor nas organizações. Entretanto, não foram encontrados estudos empíricos relacionando especificamente a reputação corporativa com o valor adicionado, representativo da criação de riqueza, conforme foco deste estudo. Dessa forma, o presente tópico expõe uma síntese de estudos empíricos que de alguma forma analisaram a relação entre a reputação corporativa e o desempenho, de uma forma geral, tanto no Brasil quanto no cenário internacional.

Fombrun e Shanley (1990) verificaram o impacto da reputação corporativa em 292 empresas britânicas listadas na revista Fortune, em 1985. Os resultados encontrados demonstram que as variáveis tamanho, desempenho financeiro (ROIC), market-to-book e o investidor institucional afetam positivamente a reputação corporativa. Em contrapartida, a variável risco impactou negativamente na reputação corporativa.

Ao investigar os fatores que podem afetar a reputação da empresa e os motivos de as reputações se modificarem ao longo do tempo nas grandes indústrias da Alemanha classificadas na Manager Magazine, entre 1988 e 1996, Dunbar e Schwalbach (2000) notaram a existência de uma relação positiva entre a reputação e o desempenho financeiro. Como indicador de desempenho, o estudo considerou o desempenho global do mercado, o qual reflete o valor de mercado e o valor contábil das empresas. Os autores concluíram que o efeito do desempenho financeiro na reputação futura da empresa é perceptível contemporaneamente, enquanto as implicações dos investimentos em reputação no desempenho financeiro futuro necessitam de um período maior para serem percebidas. Os resultados desse estudo reforçam a análise da reputação corporativa à luz do que preconiza a Teoria da Sinalização.

Roberts e Dowling (2002) realizaram pesquisa com o objetivo de examinar o impacto da reputação corporativa no desempenho financeiro das empresas, constatando uma correlação positiva entre a reputação e o crescimento e a sustentabilidade do desempenho, na medida em que as empresas com boa reputação são mais aptas a conquistar o aumento da lucratividade $e$ a sua sustentabilidade ao longo do tempo. Os autores analisaram as empresas mais admiradas da América, da revista Fortune, durante o período de 1984 a 1998, sendo o desempenho financeiro representado pelo ROA (Retorno sobre o Ativo).

Integrando também a lista de estudos empíricos anteriores, Rose e Thomsen (2004) analisaram a associação entre a reputação corporativa e o valor de mercado de empresas dinamarquesas classificadas na revista Berlingske Nyhedsmagasin, entre 1996 e 2001. As análises estatísticas apontaram que a reputação corporativa não impacta no valor da empresa, enquanto o desempenho financeiro, representado pelo grau de intangibilidade, influencia positivamente a reputação corporativa.

Numa abordagem semelhante à anterior, Inglis, Morley e Sammut (2006) procuraram testar a associação entre a reputação corporativa e o desempenho organizacional em 77 empresas australianas listadas no RepuTex, em 2003 e 2004. Para operacionalizar o desempenho corporativo, foram utilizadas quatro medidas, a saber: ROA (Retorno sobre o Ativo), ROE (Retorno sobre o Patrimônio Líquido), ROI (Retorno sobre o Investimento) e market-to-book. Contudo, diferentemente dos achados de Rose e Thomsen (2004), os resultados do estudo não sinalizaram qualquer relação entre as duas variáveis.

O estudo realizado por Sánchez e Sotorrío (2007) se propôs a conceber um modelo teórico do processo de criação de valor a partir da reputação das empresas, de modo a testar a existência de relação entre o desempenho social (medido pela reputação) e o desempenho financeiro (criação de valor), assim como os fatores que a determinam. Foram objeto de 
estudo as 100 empresas espanholas mais conceituadas, de acordo com o índice Merco no ano 2004, sendo a criação de valor mensurada por intermédio do ROA e da margem operacional bruta. Os resultados dos testes demonstraram que há uma relação positiva, não linear, entre o desempenho social e o desempenho financeiro.

Ao pesquisar, também, sobre a associação entre a reputação e a geração de valor, Horiuchi (2010) analisou as empresas mais admiradas do Brasil (CARTA CAPITAL, 2012), no período de 2002 a 2005, utilizando como variável de desempenho o valor de mercado das ações. Os resultados indicaram haver uma relação entre a reputação corporativa e o valor de mercado, já que as empresas com melhor reputação corporativa, segundo o ranking das empresas mais admiradas do Brasil, conseguiram maior avaliação pelo mercado de ações.

Caixeta et al. (2011) estudaram possíveis relações entre a reputação, medida pelas dimensões governança, desempenho e produtos e serviços, e o desempenho econômico-financeiro em cinco grandes grupos empresariais brasileiros: Embraer, Pão de Açúcar, Petrobras, Vale e Votorantim. Para o desempenho, foram empregados os seguintes indicadores: receita operacional bruta, receita operacional líquida, Ebitda, lucro bruto, lucro operacional, lucro líquido, ativo total, patrimônio líquido e investimentos no período (excluídas as aquisições). Os autores detectaram que as percepções sobre reputação nas três dimensões consideradas (governança, desempenho e produtos $e$ serviços) não apresentam relação direta com os indicadores econômico-financeiros empregados.

O estudo realizado por Cardoso et al. (2013) investigou a relação entre a reputação corporativa $e$ o desempenho das empresas com melhor reputação, conforme a classificação do Reputation Institute, no ano 2011, utilizando o $Q$ de Tobin para operacionalizar o desempenho. Os resultados indicaram que as empresas com melhor reputação corporativa apresentam desempenho superior, podendo-se concluir que a boa reputação corporativa se relaciona positivamente com o desempenho empresarial.

Em pesquisa mais recente, Domingos e Moura (2013) analisaram a associação entre a reputação corporativa, sob o enfoque da sustentabilidade, e o desempenho nas 100 maiores companhias abertas listadas no ranking da revista Exame Melhores e Maiores para o período de 2011. Como indicadores de desempenho foram utilizados: margem Ebitda, margem líquida, ROA, ROE e alavancagem financeira. Os autores concluíram que nenhuma evidência pode ser inferida no tocante à relação entre os dois aspectos, haja vista que não foi detectada diferença estatisticamente significante entre os indicadores das empresas com reputação e os daquelas sem reputação.

Mota et al. (2013) examinaram a influência das dimensões da reputação corporativa (econômica, ambiente de trabalho, sustentabilidade e governança) nos indicadores de desempenho de 255 empresas de capital aberto listadas na BM\&FBovespa. Similarmente ao procedido no estudo de Domingos e Moura (2013), foram utilizados os indicadores Ebitda, margem líquida, ROA, ROE e alavancagem financeira para operacionalizar o desempenho empresarial. Os autores constataram a influência da reputação, na perspectiva econômica, sobre os indicadores de desempenho ROA, alavancagem financeira e Ebitda. As demais dimensões da reputação não apresentaram significância estatística, $e$, portanto, não influenciaram o desempenho. Na perspectiva da sustentabilidade, os resultados corroboram os achados de Domingos e Moura (2013), que também apontaram não haver relação entre a sustentabilidade de uma empresa e o seu desempenho econômico-financeiro. Tischer e Hildebrandt (2014) analisaram a influência da publicação de rankings de reputação no preço das ações de empresas da Alemanha listadas no ranking da Manager Magazine, entre 1998 e 2008. Para tanto, os autores consideraram oscilações relativas na medida de reputação em relação aos rankings anteriores e a média geral, utilizando como métrica de desempenho o fluxo de caixa ajustado. Os resultados apontaram que o anúncio de mudanças positivas (ou negativas) na reputação impacta no valor do acionista na mesma direção. Entretanto, o estudo constatou também que outros fatores se sobrepõem à influência da reputação corporativa sobre o preço das ações no longo prazo.

Além de não haver um consenso nos resultados apresentados, o que indica a necessidade de continuidade de pesquisas sobre o tema, reforça-se a justificativa da presente pesquisa ao relacionar a reputação corporativa com a riqueza criada pelas empresas, levando-se em conta a ausência de pesquisas que utilizem essa variável (valor adicionado) como indicador do desempenho empresarial. 


\section{Metodologia}

O delineamento desta pesquisa se deu em função do objetivo, da abordagem do problema e dos procedimentos. Trata-se de estudo descritivo quanto aos objetivos, porque identifica e obtém informações sobre as características de um problema específico (COLLIS; HUSSEY, 2005). Quanto à abordagem, é de natureza quantitativa, pois se utiliza da coleta de dados para testar a hipótese com base na medição numérica, recorrendo-se à análise estatística para estabelecer padrões de comportamento (SAMPIERI; COLLADO; LÚCIO, 2013). Quanto aos procedimentos, a pesquisa é considerada documental, por utilizar dados e materiais não editados. (MARTINS; THEÓPHILO, 2009)

A amostra do estudo se caracteriza como não probabilística. De início, definiu-se a população da pesquisa, utilizando-se como referência todas as empresas listadas na BM\&FBovespa em 02/09/2013, excluindo-se as do setor financeiro e aquelas que não possuíam classificação setorial segundo o website da BM\&FBovespa, totalizando 331 empresas. Dessas, somente 309 empresas apresentaram Demonstração do Valor Adicionado referente ao exercício findo em 31/12/2012. A partir desse grupo, foram identificadas as empresas que participavam em pelo menos um dos seguintes rankings, elaborados com base em dados de 2011: as marcas mais valiosas do Brasil (ISTOÉ DINHEIRO, 2012), as 500 maiores empresas por vendas (EXAME, 2012), as 100 maiores empresas por valor de mercado (EXAME, 2012), e as empresas mais admiradas no Brasil (CARTA CAPITAL, 2012). Desse modo, a amostra do estudo ficou definida em 309 empresas, sendo 138 que possuem reputação corporativa, ou seja, participam em pelo menos um dos rankings, e 171 que não participam em nenhum dos quatro rankings.

A escolha dos quatro rankings se deu pelas suas distintas perspectivas de análise - econômico-financeira, ambiental e social -, considerando o disposto por Davies et al. (2003), segundo os quais a reputação corporativa pode ser mais bem estudada aplicando-se uma abordagem interdisciplinar.

O ranking as marcas mais valiosas do Brasil (ISTOÉ DINHEIRO, 2012) considera duas dimensões: a financeira, representada pelo valor dos ativos intangíveis, dado pela diferença entre o valor econômico e o valor contábil dos ativos tangíveis; e a de mercado, que é a contribuição da marca, representada por uma parcela do resultado da dimensão financeira.
Os rankings as 500 maiores empresas por vendas (EXAME, 1012) e as 100 maiores empresas por valor de mercado (EXAME, 2012) são constituídos pelos valores das receitas de vendas e do valor de mercado, em ordem decrescente, respectivamente.

O ranking as empresas mais admiradas no Brasil (CARTA CAPITAL, 2012) utiliza um conjunto de fatores que representa a admiração: ética, inovação, qualidade de produtos e serviços, respeito pelo consumidor, solidez financeira, qualidade de gestão, desenvolvimento sustentável, compromisso com $\mathrm{RH}$, responsabilidade social, notoriedade, capacidade com o país e as mais presentes nas redes sociais. Para a construção do ranking, são realizadas entrevistas, por telefone, com executivos no Brasil.

Para a variável independente reputação corporativa, adotou-se a defasagem temporal, em que a reputação de um exercício (rankings de 2011, publicados em 2012) impacta na criação de riqueza do exercício posterior (2012), pois, segundo Roberts e Dowling (2002), a reputação corporativa é criada com o tempo, de modo que o seu efeito só se verifica em períodos subsequentes.

Os dados referentes à criação de riqueza (valor adicionado), variável dependente, foram extraídos das DVAs das empresas, referentes ao exercício findo em 31/12/2012. Cabe ressaltar que o valor adicionado é obtido pela diferença entre o valor das vendas e o dos insumos (bens e serviços) adquiridos de terceiros (DE LUCA et al., 2009).

Já os dados alusivos às variáveis de controle tamanho, ativos intangíveis, endividamento, idade e internacionalização - foram extraídos das Demonstrações Financeiras Padronizadas - Balanço Patrimonial e DVA - e do Formulário de Referência referentes ao exercício de 2012.

Para a análise da relação entre a reputação corporativa e a criação de riqueza das empresas de capital aberto listadas na BM\&FBovespa, fez-se uso da Regressão Linear Múltipla, sendo adotada nesta pesquisa a Equação 1, a seguir:

$$
\begin{aligned}
& \mathrm{CRi}=\alpha+\beta 1 \mathrm{REPi}+\beta 2 \mathrm{TAMi}+\beta 3 \mathrm{PAIi}+\beta 4 \mathrm{ENDi}+ \\
& \beta 5 \mathrm{IDAi}+\beta 6 \mathrm{INTi} \\
& \text { (Equação 1) }
\end{aligned}
$$

O Quadro 1 apresenta as variáveis dependente, independente e de controle utilizadas na Regressão Linear Múltipla. 


\begin{tabular}{|c|c|c|c|c|}
\hline \multicolumn{2}{|c|}{ VARIÁVEL } & \multirow{2}{*}{$\begin{array}{c}\text { MÉTRICA } \\
\text { Criação de Riqueza: } \\
\text { Valor Adicionado }\end{array}$} & \multirow{2}{*}{$\begin{array}{l}\text { OPERACIONALIZAÇÃo } \\
\text { Ln do valor adicionado }\end{array}$} & \multirow{2}{*}{$\begin{array}{c}\text { FonTE DE ColeTA } \\
\text { Demonstração do Valor Adicionado }\end{array}$} \\
\hline $\begin{array}{l}\text { Variável De- } \\
\text { pendente }\end{array}$ & CR & & & \\
\hline $\begin{array}{l}\text { Variável In- } \\
\text { dependente }\end{array}$ & REP & Reputação Corporativa & $\begin{array}{l}\text { Para cada ranking, foi } \\
\text { atribuído } 1 \text { ponto às empresas } \\
\text { que o compõem e } 0 \text { para } \\
\text { as que não o compõem } \\
\text { A REP será o somatório } \\
\text { dos pontos dividido pela } \\
\text { quantidade de rankings }\end{array}$ & $\begin{array}{l}\text { Rankings } \\
\text { As marcas mais valiosas do Brasil, } \\
\text { As } 500 \text { maiores empresas por vendas } \\
\text { As } 100 \text { maiores empresas } \\
\text { por valor de mercado } \\
\text { As empresas mais admiradas no Brasil }\end{array}$ \\
\hline \multirow{5}{*}{$\begin{array}{l}\text { Variáveis de } \\
\text { Controle }\end{array}$} & TAM & Tamanho & Ln do Ativo Total & Balanço Patrimonial \\
\hline & PAI & $\begin{array}{l}\text { Proporção de Ativos } \\
\text { intangíveis }\end{array}$ & Ativo Intangível / Ativo Total & Balanço Patrimonial \\
\hline & END & Endividamento & $\begin{array}{l}\text { (Ativo Total - Patrimônio } \\
\text { Líquido) / Ativo Total }\end{array}$ & Balanço Patrimonial \\
\hline & IDA & Idade & $\begin{array}{l}\text { Ln }(2012 \text { - data de } \\
\text { constituição) }\end{array}$ & Formulário de Referência \\
\hline & INT & Internacionalização & $\begin{array}{l}\text { Concentração acionária } \\
\text { de capital estrangeiro }\end{array}$ & Formulário de Referência \\
\hline
\end{tabular}

Quadro 1: Variáveis utilizadas no modelo de regressão

Fonte: Elaborado pelos autores deste artigo

A adoção das variáveis de controle se deu com base em estudos anteriores, como o de Roberts e Dowling (2002), que também procurou verificar a influência de alguns fatores no desempenho das organizações.

Para verificar se a criação de riqueza das empresas com reputação corporativa é estatisticamente similar à das demais, recorreu-se ao teste de diferenças entre médias de Mann-Whitney, em que as 309 empresas da amostra foram distribuídas em dois grupos: Grupo 1, constituído por 138 empresas que detêm reputação corporativa, ou seja, participam em pelo menos um dos quatro rankings já mencionados; e Grupo 2, reunindo as 171 empresas que não detêm reputação corporativa, por não participar dos quatro rankings.
O tratamento dos dados (Regressão Linear Múltipla e teste de Mann-Whitney) foi realizado com o auxílio do aplicativo Statistical Package for the Social Sciences (SPSS), versão 21.

\section{Análise dos Resultados}

Inicialmente, realizou-se uma análise descritiva dos dados, a fim de se verificar o seu comportamento. A Tabela 1 apresenta os valores mínimos e máximos, assim como a média, o desvio-padrão e o coeficiente de variação das variáveis utilizadas no estudo.

Tabela 1: Estatística descritiva

\begin{tabular}{|c|c|c|c|c|c|c|}
\hline VARIÁveL & NÚMERO & Mínimo & Máxıмo & MÉDIA & DESVIO-PADRÃo & $\begin{array}{l}\text { COEFICIENTE DE } \\
\text { VARIAÇÃo (\%) }\end{array}$ \\
\hline $\begin{array}{l}\text { Criação de } \\
\text { riqueza }\end{array}$ & 309 & 474,00 & $\mathrm{R} \$ 201.574 .312,00$ & $\mathrm{R} \$ 3.654 .593,26$ & $\mathrm{R} \$ 16.964 .878,87$ & 464 \\
\hline Reputação & 309 & 0,00 & 1,00 & 0,2296 & 0,31527 & 137 \\
\hline Tamanho & 309 & 110,00 & $\mathrm{R} \$ 677.716 .287,00$ & $\mathrm{R} \$ 11.716 .078,95$ & $\mathrm{R} \$ 50.710 .956,17$ & 433 \\
\hline Endividamento & 309 & 0,0003 & 245,5511 & 2,020579 & 15,5080341 & 768 \\
\hline $\begin{array}{l}\text { Proporção de } \\
\text { ativos intangíveis }\end{array}$ & 309 & 0,00 & 0,94 & 0,1699 & 0,23702 & 140 \\
\hline Idade & 309 & 1 & 140 & 37,1299 & 29,08772 & 78 \\
\hline $\begin{array}{l}\text { Internaciona- } \\
\text {-lização }\end{array}$ & 309 & 0,00 & 1,00 & 0,07417467 & 0,16657027 & 225 \\
\hline
\end{tabular}

Fonte: Dados da pesquisa 
Observa-se que todas as variáveis se caracterizam pela alta heterogeneidade dos dados, evidenciando, assim, uma grande dispersão na amostra. A criação de riqueza, mensurada a partir do valor adicionado, apresenta um valor médio de $\mathrm{R} \$ 3.654 .593,26$. Na comparação com o valor máximo, o valor médio representa apenas $1,81 \%$. A reputação corporativa de todas as 309 empresas da amostra, mensurada por meio de um conjunto de rankings, possui o valor médio correspondente a $22,96 \%$.

Quanto ao tamanho, em média, as empresas são consideradas de grande porte. Já em relação ao endividamento, variável com maior coeficiente de variação, tem-se na amostra empresas praticamente não endividadas, bem como empresas com alto endividamento, que, no caso mais extremo, chega a ser de $245 \%$, hipótese em que a empresa apresenta patrimônio líquido negativo. Quanto à proporção de ativos intangíveis, pode-se observar que há empresas que não possuem esse tipo de direito, enquanto em outras os ativos intangíveis correspondem a quase $100 \%$ do Ativo Total, caso das empresas do setor de exploração de rodovias, cujas concessões constituem seu principal ativo. Verificando-se o tempo de constituição (idade), o estudo apresenta empresas jovens, assim como empresas centenárias, sendo estas de diversos setores. Quanto à internacionalização, mensurada por meio da proporção de capital estrangeiro, pode-se verificar que a amostra é composta de empresas que não detêm acionistas estrangeiros entre os principais acionistas, conforme demonstrado no Formulário de Referência, enquanto em outras o capital é integralmente pertencente a acionistas estrangeiros.

Após a análise descritiva dos dados, realizou-se a Regressão Linear Múltipla, de forma a atender o objetivo geral do estudo. Desse modo, a Tabela 2 apresenta os dados que evidenciam a relação entre a reputação corporativa $e$ a criação de riqueza nas empresas pesquisadas.

Tabela 2: Resultado da Regressão Linear Múltipla

\begin{tabular}{|c|c|c|c|c|}
\hline Modelo & \multicolumn{2}{|c|}{ B } & SIG. & VIF \\
\hline (Constante) & $-0,963$ & $(* *)$ & 0,026 & - \\
\hline $\begin{array}{l}\text { Reputação } \\
\text { Corporativa }\end{array}$ & 0,526 & $(* * *)$ & 0,002 & 1,363 \\
\hline Tamanho & 0,888 & $(* * *)$ & 0,000 & 1,447 \\
\hline
\end{tabular}

\begin{tabular}{|c|c|c|c|c|}
\hline Modelo & \multicolumn{2}{|c|}{ B } & Sig. & VIF \\
\hline Endividamento & 0,007 & $(* *)$ & 0,050 & 1,051 \\
\hline $\begin{array}{c}\text { Proporção de } \\
\text { Ativos Intangíveis }\end{array}$ & 0,873 & $(* * *)$ & 0,000 & 1,150 \\
\hline Idade & 0,305 & $(* * *)$ & 0,000 & 1,158 \\
\hline Internacionalização & $-0,008$ & $(* * *)$ & 0,009 & 1,030 \\
\hline $\mathbf{R}^{2}$ & 84,500 & $\mathbf{R}^{2}$ ajustado & 84,200 \\
\hline Teste F & 274,711 & $(* * *)$ & $\begin{array}{c}\text { Durbin- } \\
\text {-Watson }\end{array}$ & 2,046 \\
\hline
\end{tabular}

Nota: $\left(^{* *}\right)$ Sig. de até $5 \% ;\left(^{* * *}\right)$ Sig. de até $1 \%$.

Fonte: Dados da pesquisa

Para proceder à regressão, foi necessário verificar o atendimento de quatro pressupostos básicos: autocorrelação, multicolinearidade, homocedasticidade e normalidade dos resíduos. Foi verificado que (i) há ausência de autocorrelação, pois o modelo apresentou Durbin-Watson próximo ao valor 2 (2,046); (ii) inexiste multicolinearidade, já que os VIF - fator de inflação de variância - estão próximos de 1; (iii) há homocedasticidade, pois o modelo de regressão dos preditos padronizados pelos resíduos padronizados foi não significante (sig. $=0,290$ ); (iv) os resíduos se mostraram normais, por meio do teste Kolmogorov-Smirnov (sig. = 0,200). Portanto, os pressupostos da regressão foram atendidos, e, desse modo, verifica-se que o modelo é válido.

Observa-se que o $\mathrm{R}^{2}$ ajustado é de $84,2 \%$, demonstrando que o modelo apresenta um alto poder explicativo, além do que este é significante de até $1 \%$, ratificando que o modelo é válido, já que esse resultado avalia a significância conjunta das variáveis explicativas.

Dessa forma, o modelo, que possui como variável dependente a criação de riqueza, apresentou significância em todas as variáveis, sendo que somente a variável internacionalização apresentou uma relação negativa com a criação de riqueza. Destarte, a reputação corporativa é um fator que influencia a criação de riqueza, sendo que, quanto melhor a reputação da empresa, maior a riqueza criada. Essa relação é também verificada para as variáveis tamanho, endividamento, proporção de ativos intangíveis e idade; logo, quanto maiores forem esses fatores, maior será a criação de riqueza. Contudo, observou-se que a maior participação estrangeira no capital (internacionalização) não favorece a criação de riqueza. 
Considerando-se o valor adicionado (riqueza criada pela empresa) como variável de desempenho, pode-se afirmar que a relação positiva entre a reputação corporativa e a criação de riqueza, encontrada no presente estudo, é corroborada pelos resultados obtidos por Fombrun e Shanley (1990), Dunbar e Schwalbach (2000), Roberts e Dowling (2002), Sánchez e Sotorrío (2007), Horiuchi (2010), Cardoso et al. (2013) e Tischer e Hildebrandt (2014), que também verificaram haver relação positiva entre a reputação $e$ o desempenho empresarial.

Nessa mesma perspectiva, os resultados da pesquisa refutam os estudos de Rose e Thomsen (2004), Inglis, Morley e Sammut (2006) e Caixeta et al. (2011), já que estes não encontraram relação entre a reputação corporativa e a criação de valor.

Pode-se afirmar, portanto, que as empresas com reputação, que são consideradas antigas, de grande porte, com alto nível de endividamento, com grande proporção de ativos intangíveis na composição do seu Ativo Total e uma baixa inserção de capital estrangeiro possuem uma maior criação de riqueza. Dessa forma, de acordo com os resultados obtidos no presente estudo, confirma-se a hipótese de que nas companhias de capital aberto listadas na BM\&FBovespa a reputação corporativa está positivamente relacionada com a criação de riqueza.

Adicionalmente, procurou-se verificar se as empresas com reputação corporativa geram maior criação de riqueza, comparativamente às demais que não possuem reputação corporativa. A Tabela 3 apresenta os resultados da análise estatística por meio da aplicação do teste de diferenças entre médias não paramétrico de Mann-Whitney, para duas amostras independentes: empresas que possuem reputação e empresas que não a possuem.

Tabela 3: Teste de diferenças entre médias de Mann-Whitney

\begin{tabular}{|c|c|c|c|c|}
\hline \multicolumn{2}{|c|}{ Reputação Corporativa } & \multirow{2}{*}{$\begin{array}{c}\mathbf{N} \\
138\end{array}$} & \multirow{2}{*}{$\begin{array}{c}\begin{array}{c}\text { Ranking } \\
\text { Médio }\end{array} \\
211,07\end{array}$} & \multirow{2}{*}{$\begin{array}{c}\begin{array}{c}\text { Soma } \\
\text { dos } \\
\text { Rankings }\end{array} \\
29.128,00\end{array}$} \\
\hline \multirow{3}{*}{$\begin{array}{c}\text { Criação } \\
\text { de } \\
\text { Riqueza }\end{array}$} & $\begin{array}{l}\text { Empresas } \\
\text { que possuem } \\
\text { reputação }\end{array}$ & & & \\
\hline & $\begin{array}{c}\text { Empresas que } \\
\text { não possuem } \\
\text { reputação }\end{array}$ & 171 & 109,75 & $18.767,00$ \\
\hline & Total & 309 & - & - \\
\hline \multicolumn{2}{|c|}{ Mann-Whitney U } & 4061,000 & $\begin{array}{l}\text { Sig. Assint. } \\
\text { (2 caudas) }\end{array}$ & 0,000 \\
\hline
\end{tabular}

Fonte: Dados da pesquisa
O teste de diferenças entre médias de Mann-Whitney revelou que houve diferenças estatisticamente significantes entre os dois grupos de empresas analisados, tendo em vista um nível de significância de $1 \%$, indicando que as empresas detentoras de reputação geram mais riqueza do que as empresas que não possuem reputação, ou seja, que não participam dos rankings de reputação considerados neste estudo. Dessa forma, ratifica-se que esses resultados corroboram os achados de Sánchez e Sotorrío (2007), Horiuchi (2010), Cardoso et al. (2013) e Tischer e Hildebrandt (2013), os quais também detectaram que a reputação corporativa está positivamente associada à criação de valor.

Com base nos resultados obtidos, e à luz da Teoria da Sinalização, identifica-se que os sinais positivos emitidos para os stakeholders se refletem em uma boa reputação e, consequentemente, contribuem para a criação de riqueza, em consonância com os argumentos expostos na revisão de literatura. Portanto, a manutenção de uma reputação perante o mercado constitui fator diferenciador quanto à criação de valor.

\section{Considerações Finais}

A presente pesquisa teve por objetivo principal investigar a relação entre a reputação corporativa e a criação de riqueza nas companhias de capital aberto listadas na BM\&FBovespa, considerando a Teoria da Sinalização como pressuposto teórico do estudo. Para tanto, a pesquisa, de cunho descritivo, com abordagem quantitativa dos dados, utilizou a Regressão Linear Múltipla e o teste de diferenças entre médias de Mann-Whitney, em uma amostra que reuniu 309 empresas listadas na BM\&FBovespa. A criação de riqueza foi representada pelo valor adicionado das empresas, obtido a partir da DVA, parte integrante das Demonstrações Financeiras Padronizadas, disponíveis no website da BM\&FBovespa.

Os resultados da regressão revelaram que a criação de riqueza está positivamente associada com a reputação corporativa - neste estudo, representada pela participação em pelo menos um dos seguintes rankings: as marcas mais valiosas do Brasil, as 500 maiores empresas por vendas, as 100 maiores empresas por valor de mercado e as empresas mais admiradas no Brasil -, podendo-se inferir que apresentar uma 
boa reputação contribui para uma maior geração de riqueza, em conformidade com o que preconiza a Teoria da Sinalização.

De modo mais específico, constatou-se que o tamanho, o endividamento, a proporção de ativos intangíveis, a idade e a internacionalização influenciam a criação de riqueza. Nessa perspectiva, observou-se que as empresas de grande porte, com elevado nível de endividamento, grande quantidade de ativos intangíveis na composição do Ativo Total e mais tempo de permanência no mercado assinalaram maior criação de riqueza. Por outro lado, verificou-se que as empresas que possuem alta inserção de capital estrangeiro (internacionalização) não apresentam uma maior riqueza criada.

Adicionalmente, a partir do teste de diferenças entre médias não paramétrico de Mann-Whitney, percebe-se que há diferenças estatisticamente significantes entre as empresas com reputação e aquelas sem reputação, ou seja, não participantes dos quatro rankings, apontando que as empresas detentoras de reputação positiva perante o mercado geram mais riqueza.

Dessa forma, manter uma boa reputação corporativa, sendo esta considerada um ativo intangível, dificilmente copiada e proveniente dos sinais positivos emitidos para os stakeholders, constitui fator determinante na explicação da criação de riqueza. Portanto, aceita-se a hipótese proposta no estudo, de que nas companhias de capital aberto listadas na BM\&FBovespa a reputação corporativa está positivamente relacionada com a criação de riqueza.

Ressalta-se que a presente análise se faz relevante no cenário acadêmico e no âmbito empresarial, pois aborda conjuntamente a reputação corporativa e a criação de riqueza como medidas de desempenho empresarial, o que ainda carece de maior discussão. Adicionalmente, a sinergia dos construtos reputação corporativa e criação de riqueza sob o enfoque da Teoria da Sinalização, por meio de uma análise estatística de alto teor de explicação, pode contribuir na investigação dos fatores preponderantes para uma maior criação de valor.

Constituem limitações deste estudo, dentre outras, a população constituída somente por empresas listadas na BM\&FBovespa e o limitado período de análise. Assim, para futuras pesquisas, sugere-se a ampliação do universo de empresas componentes da base amostral e do intervalo temporal de investigação, como forma de possibilitar a análise da evolução dos dados em cenários distintos. Recomenda-se, ainda, a adição de outros rankings que gerem uma medida multidimensional para a análise da reputação corporativa.

\section{ReferêNCIAS}

\section{BALMER, J. M. T.; GREYSER, S. A. Revealing the}

corporation: perspectives on identity, image, reputation, corporate branding, and corporate-level marketing: an anthology. London: Routledge, 2003.

BRITO, R. P.; BRITO, L. A. L. Vantagem competitiva, criação de valor e seus efeitos sobre o desempenho.

Revista de Administração de Empresas, São Paulo, v. 52, n. 1, p. 70-84, 2011.

CAIXETA, C. G. F.; et al. Reputação corporativa e desempenho econômico-financeiro: um estudo em cinco grandes grupos empresariais brasileiros. Revista

Eletrônica de Gestão Organizacional, Recife, v. 1, n. 9 , p. 86-109, 2011.

CARDOSO, V. I.; et al. Reputação corporativa como fator propulsor do desempenho empresarial. In: CONGRESSO ANPCONT, 7., 2013, Fortaleza. Anais... Fortaleza:

Associação Nacional dos Programas de Pós-Graduação em Ciências Contábeis, 2013.

\section{CARTA CAPITAL. As empresas mais admiradas no}

Brasil. São Paulo: Confiança, 2012.

\section{CASTRO, D. J. Como se constrói uma "reputação} corporativa"? 2008. 170f. Dissertação (Mestrado em Administração de Empresas) - Escola de Administração de Empresas de São Paulo, Fundação Getúlio Vargas, São Paulo, 2008.

CHUN, R. Corporate reputation: meaning and measurement. International Journal of Management Reviews, London, v. 7, n. 2, p. 91-109, 2005.

\section{COLLIS, J.; HUSSEY, R. Pesquisa em administração:}

um guia prático para os alunos de graduação e pósgraduação. 2. ed. Porto Alegre: Bookman, 2005.

DALMÁCIO, F. Z. et al. Uma análise da relação entre governança corporativa e acurácia das previsões 
dos analistas do mercado brasileiro. Revista de

Administração Mackenzie, São Paulo, v. 14, n. 5, 2013.

DAVIES, G. et al. Corporate reputational and competitiveness. London: Routledge, 2003.

DE LUCA, M. M. M. et al. Demonstração do valor adicionado: do cálculo da riqueza criada pela empresa ao valor do PIB. 2. ed. São Paulo: Atlas, 2009.

DOMINGOS, S. R. M.; MOURA, A. A. F. Reputação corporativa e desempenho: uma análise nas maiores companhias abertas do Brasil. In: CONGRESSO USP DE CONTROLADORIA E CONTABILIDADE, 13., 2013, São Paulo. Anais...São Paulo, Universidade de São Paulo, 2013.

\section{DOWLING, G. Creating corporate reputations -} identity, image and performance. New York: Oxford University Press: 2001.

Communicating corporate reputation through

stories. California Management Review, Berkeley, v. 48, n. 1, p. 82-100, 2006.

DUNBAR, R. L. M.; SCHWALBACH, J. Corporate reputation and performance in Germany. Corporate

Reputation Review, London, v. 3, n. 2, p. 115-123, 2000.

EXAME. Melhores e maiores: as 1.000 maiores empresas do Brasil, São Paulo: Abril, 2012.

FOMBRUN, C. J.; SHANLEY, M. What's in a name? Reputation building and corporate strategy. Academy of Management Journal, Mississippi, Briarcliff Manor, v. 33, n. 2, p. 233-58, 1990.

; GARDBERG, N. A.; SEVER, J. M. The reputation quotientSM: a multi-stakeholder measure of corporate reputation. The Journal of Brand Management, Bradford, v. 7, n. 4, p. 241-255, 2000.

; VAN RIEL, C. The reputational landscape.

Corporate Reputation Review, London, v. 1, n. 1/2, p. 5-13, 1997.

GOMES, G. A. et al. Responsabilidade socioambiental corporativa e indicador de maturidade mediando desempenho estratégico para as organizações. Revista de Ciências da Administração, Florianópolis, v. 12, n. 26, p. 244-269, 2010.

GONZÁLEZ, P. G. As mudanças nas políticas de dividendos e o mercado financeiro. Caderno de

Estudos, São Paulo, n. 19, p. 1-12, 1998.

HALL, R. The strategic analysis of intangible resources.

Strategic Management Journal, Candler, v. 13, n. 2, p. 135-144, 1992.

HERREMANS, I. M.; AKATHAPORN, P.; McINNES, M. An investigation of corporate social responsibility reputation and economic performance. Accounting Organizations and Society, Amsterdam, v. 18, p. 587-604, 1993.

HORIUCHI, W. S. Reputação corporativa: impacto no valor de mercado das companhias abertas brasileiras. 2010. 61 f. Dissertação (Mestrado em Administração) Instituto de Ensino e Pesquisa, São Paulo, 2010.

HUSTED, B. W.; ALLEN, D. B. Strategic corporate social responsibility and value creation among large firms: lessons from the Spanish experience. Long Range Planning, Amsterdam, v. 40, p. 594-610, 2007.

INGLIS, R.; MORLEY, C.; SAMMUT, P. Corporate reputation and organizational performance: an Australian study. Managerial Auditing Journal, Bradford, v. 21 n. 9, p. 934-947, 2006.

ISTOÉ DINHEIRO. As marcas mais valiosas do Brasil, São Paulo: Três, 2012.

JORGE, N. S. Reputação: um elemento diferenciador e protetor face a crises organizacionais. 2010. 127f. Dissertação (Mestrado em Gestão Estratégica das Relações Públicas) - Escola Superior de Comunicação Social, Instituto Politécnico de Lisboa, Lisboa, 2010.

KLANN, R. C.; BEUREN, I. M. Características de empresas que influenciam o seu disclosure voluntário de indicadores de desempenho. Brazilian Business Review, Vitória, v. 8, n. 2, p. 97, 2011.

LANDON, S.; SMITH, C. E. The use of quality and reputation indicators by consumers: the case of bordeaux wine. Journal of Consumer Policy, New York, v. 20, p. 289-323, 1997.

\section{MACHADO FILHO, C. P. Responsabilidade social e} governança: o debate e as implicações: responsabilidade social, instituições, governança e reputação. São Paulo: Pioneira Thomson Learning, 2006. 
MARTINS, G. A.; THEÓPHILO, C. N. Metodologia da investigação científica para ciências sociais aplicadas. São Paulo: Atlas, 2009.

MOTA, A. F; DE LUCA, M. M. M.; VASCONCELOS, A. C.; CARDOSO, V. I. C. Reputação corporativa e indicadores empresariais: uma abordagem à luz da Teoria da Sinalização. In: CONGRESSO ADCONT, 4., 2013, Rio de Janeiro. Anais... Rio de Janeiro: Universidade Federal do Rio de Janeiro, 2013.

PETERAF, M. A.; BARNEY, J. B. Unraveling the resourcebased tangle. Managerial and Decision Economics, [S.1.], v. 24, n. 4, p. 309-323, 2003.

RIAHI-BELKAOUI, A. Value added reporting: lessons for the United States. New York: Quorum Books, 1992.

ROBERTS, P. W.; DOWLING, G. R. Corporate reputation and sustained superior financial performance. Strategic Management Journal, Candler, v. 23, n. 12, p. 1.0771.093, 2002.

ROSE, C.; THOMSEN, S. The impact of corporate reputation performance: some Danish evidence.

European Management Journal, Amsterdam, v. 22, n. 2, p. 201-2.010, 2004.

SAMPIERI, R. H.; COLLADO, C. F.; LÚCIO, P. B. Metodologia de pesquisa. 3. ed. São Paulo: McGraw Hill, 2013.

SÁNCHEZ, J.; SOTORRÍO, L. The creation of value through corporate reputation. Journal of Business Ethics, New York, v. 76, n. 3, p. 335-343, 2007.

\section{SANTOS, A. Demonstração do valor adicionado:} como elaborar e analisar a DVA. 2. ed. São Paulo: Atlas, 2007.

SANTOS, P. M. F.; PORTO, R. B. A gestão ambiental como fonte de vantagem competitiva sustentável: contribuições da visão baseada em recursos e da teoria institucional. Revista de Ciências da Administração, Florianópolis, v. 15, n. 35, p. 152-167, 2013.

SPENCE, M. Job market signaling. The Quartely

Journal of Economics, Oxford, v. 87, n. 3, p. 355-374, 1973.
THOMAZ, J. C.; BRITO, E. P. Z. Reputação corporativa: construtos formativos e implicações para a gestão.

Revista de Administração Contemporânea, Rio de Janeiro, v. 14, n. 2, p. 229-250, 2010.

TISCHER, S.; HILDEBRANDT, L. Linking corporate reputation and shareholder value using the publication of reputation rankings. Journal of Business Research, Amsterdam, 2013. Disponível em: <http://dx.doi. org/10.1016/j.jbusres.2013.08.007>. Acesso em: 13 jan. 2014. 